Review article

\title{
The mutual responses of higher plants to environment: Physiological and microbiological aspects
}

\author{
Wu Gang ${ }^{\text {a,e }}$, Wei Zhen-Kuan ${ }^{\text {a,d }}$, Wang Yong-Xiang ${ }^{\text {a,d }}$, \\ Chu Li-Ye ${ }^{\mathrm{a}, \mathrm{c}, \mathrm{d}}$, Shao Hong-Bo ${ }^{\mathrm{a}, \mathrm{b}, \mathrm{c}, \mathrm{e}, *}$ \\ ${ }^{a}$ State Key Laboratory of Urban and Regional Ecology, Research Center for Eco-Environmental Sciences, \\ Chinese Academy of Sciences, Beijing 100085, China \\ ${ }^{\mathrm{b}}$ Binzhou University, Binzhou 256603, China \\ ${ }^{\mathrm{c}}$ Institute of Life Sciences, Qingdao University of Science \& Technology, Qingdao 266042, China \\ ${ }^{\mathrm{d}}$ Graduate School of Chinese Academy of Sciences, Beijing 100049, China \\ ${ }^{\mathrm{e}}$ Qingdao Institute of Biomass Energy and Bioprocess Technology, Chinese Academy of Sciences, Qingdao 266071, China
}

Received 16 April 2007; received in revised form 2 May 2007; accepted 3 May 2007

Available online 22 May 2007

\begin{abstract}
Higher plants are different from animals in many aspects, but the important difference may be that plants are more easily influenced by environment. Plants have a series of fine mechanisms for responding to environmental changes, which has been established during their longperiod evolution and artificial domestication. The relationship between higher plants and environment is influenced mutually. The component in environment provides higher plants with nutrients for shaping themselves and higher plants simultaneously bring photosynthetic products and metabolites to surroundings, which is the most important part of natural circle. Photosynthetic products are realized mainly by physiological mechanisms, and microbiological aspects in environment (for instance, soil environment) impact the above processes greatly. The complete understanding of the relationship will extremely promote the sustainable utilization of plant resources and make the best use of its current potential under different scales.
\end{abstract}

(C) 2007 Elsevier B.V. All rights reserved.

Keywords: Higher plants; Soil-root interface; Gene regulatory network system; Environment; Abiotic stress; Mycorrhizal fungal community

\section{Contents}

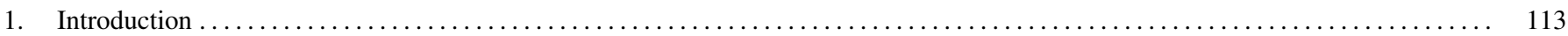

2. Physiological theories: understanding higher plant physiological function realization under changing environment ............ 114

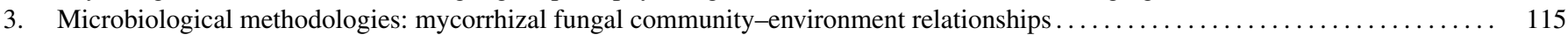

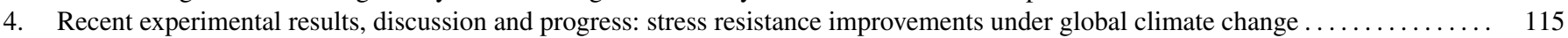

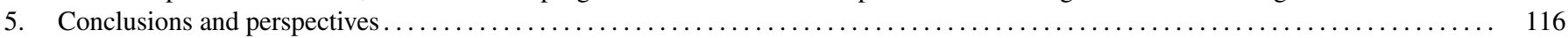

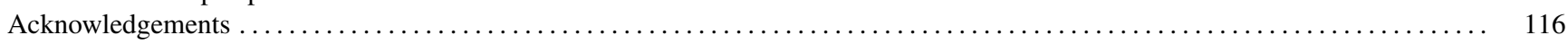

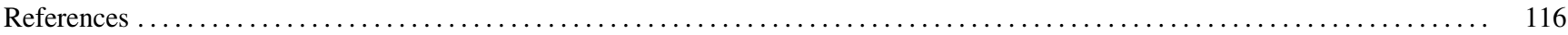

* Corresponding author at: Institute of Life Sciences, Qingdao University of Science \& Technology, Zhengzhou Road 53, Qingdao 266042, China. Tel.: +86532 84022506; fax: +8653284023271.

E-mail address: shaohongbochu@126.com (S. Hong-Bo).

\section{Introduction}

Physiological and microbiological responses of higher plants to environment have been studied extensively over the world, especially by targeting model plants and crop plants [1-19]. Abiotic stresses in environment are linked with all the living process of higher plants and greatly influence plant productivity [20-61]. Character expressions of higher plants are controlled by 
developmental cues and environmental stimuli, most of which are the important factors affecting eco-environment such as low temperature, drought, salinity and UV-B radiation, which often occur in terrestrial ecosystem. Understanding the mechanisms by which higher plants perceive environmental stimuli and transmit the signals (stimuli) to cellular machinery to activate adaptive responses is of vital importance to modern molecular biology. Deep knowledge about stress signal transduction is also the basis for continuous development of crop breeding and transgenic strategies to improve stress tolerance in forest, grass, crops, decomposition of poisonous substances of circumstance, and vegetation succession [62-96]. During the 21st century, sustainable-healthy utilization for environment and resources and human being own health concerns are the most important issues $[97,98]$. This issue is tightly linked with agriculture (food) and eco-environment, in which plant biology plays the greatest role, because plants provide the globe with its only renewable resource of food, building material and energy [91-96]. Plant biology is the most powerful tool to reasonably use natural resources [99-137]. In the wide field of plant biology, its core is the study for life activities at molecular level, whose interactions at various soil-root biointerfaces at different scales are quite important to keep a steady state between plants and changing environment, especially adverse surroundings. In practice, the key point to agriculture is how to regulate the harmonious relationship between soil-environment and crops and make the best of physiological potential of crops [137-147]. So, adaptation in plants is an important topic in basic and applied biology under global climate change [11,15-19,43-48,104-107,120]. In the discipline context, it is very interesting to understand the interaction between plants and their environment. It is also a urgent need for human life that we should create crop plants that are able to confront successfully unfavorable natural conditions $[7,10,11,128-134,144]$. The main aim in plant breeding is to obtain plants that combine higher yields, reliable yield stability, better quality and obvious characters resisting stresses (abiotic and biotic) over years and locations [15,16,22,36]. However, in addition to biotic stress factors, disturbances of extreme or even mild abiotic stress are supposed to account for a high amount of unachieved potential in plant production all over the globe $[22,23,72,73,77,78]$. Diverse forms of abiotic stresses may occur, including drought, cold and freezing, heat, salinity, nutrient deficiency, toxic heavy metals, oxidative stress as well as oxygen shortage, and mechanical stress [37,88,115]. Although it is accepted that diverse environmental stress factors never act alone, experimental study of plant responses to abiotic stresses is normally restricted to plant reactions on isolated stress factors [2-6,134,144-147]. However, it has to be considered that stress always occurs as a complex of various interacting environmental factors that contribute in varying degrees to the overall stressed phenotype [72,73,97-109]. Consequently, plants usually respond to a unique complex of growth conditions [13,16,77,78,117,124-126]. Abiotic and biotic stress factors have some common signal and responding pathways in plants and thereby can be utilized potentially by cross-signaling $[14,93,118,119]$. Further, sessile plants have to get alone with the dynamics of changing environmental conditions and have the flexibility for responding to these complicated changes $[10,11,15,16]$, and this has to be achieved at the various stages of plant development [23,24,37,40,47,102-109]. Considering the interacting complexity (at least including water movement, solute transport, information exchange, ion homeostasis regulation, and other related physi-chemical changes) between plants and their surroundings, it is important to understand physiological functions for higher plants under environment. In this article, related aspects of physiological and microbiological responses of higher plants to environment will be reviewed, mainly including the following parts: plant physiological function realization under changing environment, microbiological aspects in soil environment, and resistance improvement under global climate change. Other aspects in this hot field will be found in the recent references.

\section{Physiological theories: understanding higher plant physiological function realization under changing environment}

Plants live in soil-plant-atmosphere continuum (SPAC) environment, and they have to coordinate the mechanisms of diverse types to respond to the above changing environment at any time for sustainable survival [4-9,21-29,47-59]. Plant production realization is obtained eventually through physiological pathways at least at the level of individual and community [102-109,120,130-140]. One molecule or cell cannot produce any economic effect in field [22,23,77,78,117]. Under the condition of ensuring plant survival, plants can produce corresponding yield. Water is one of key factors influencing plant production and many reports have proved this clearly. Loss of water in soil will lead to great reduction in plant production, which has been reflected from total grain yield of many countries in the world. Water is the important material for photosynthetic reactions that plants depend on to finish accumulation of photosynthetic products, which are impacted greatly by physiological pathways and environmental factors (such as soil water supply and mineral nutrients in soil) [34-37,60-66]. So, different soil water supply will result in quite different physiological pathways, which directly determine the ability for plants to make photosynthetic products. Water deficits in soil environment also influence solute transport (ion and nutrient uptake of plants) to larger extent, which effects on photosynthetic reactions in plant chloroplasts in many ways $[117,120,131,135,139-147]$. This is the reason that ion homeostasis and redox state have been brought to attention [4-7,21-29,111-119]. The series of the above reactions and processes occurring at different soil-root biointerfaces is regulated and controlled by plant gene regulatory network system spatially and temporally on the basis of responding to plant developmental cues, through which plants can elegantly respond to the changing environment [8-18,45-49,62,76-79,94-98]. This network system has been formed by the interaction between plants and environment for a long time of evolution, which will continue to evolve with environmental succession $[10,11,17,18]$. From the angle of individual plant development, Plant Growth Grand Periodicity curve can reflect and show the above trend [4-9,102-109,136-140]. Besides, plant responses to soil water 
deficits take a "slow-fast-slow" shaped curve in terms of main physio-biochemical indices change and this is in agreement with Plant Growth Grand Periodicity, which also illustrates this fact and the wide plasticity for plants [29,31,32,101,102]. Surely, concerted expression of corresponding genes in plant gene regulatory network system makes it possible that we can see the phenotype and phenotype change under given temporal-spatial condition $[23,24,82,83,93,95]$.

\section{Microbiological methodologies: mycorrhizal fungal community-environment relationships}

Mycorrhizal fungal community plays an important role in soil environment quality and natural circle, also influencing higher plant functions to a large extent $[6,7,127-134]$. Our understanding of the controls on mycorrhizal fungal species distribution and community organization is in its early childhood, especially when compared with that of the more mature fields of plant and animal community ecology and biogeography. This is due to the historical difficulty of gathering species distribution information [120,127-130]. This challenge, arising from the paucity of mycorrhizal morphological characteristics, is magnified because of high diversity, particularly in ectomycorrhizal fungal communities $[127,128]$. The application of molecular tools has allowed us to move forward with many detailed below-ground mycorrhizal community analyses $[6,11,44,45,145]$. Much of these work has been linked with experiments, gradients and chronosequences, leading to an increased understanding of environmental controls on species distribution and abundance [127-129]. As an essential step, the above studies are mostly conducted at a local scale, and this resulted in a fragmented picture of species distribution and relationship with the environment, which cannot be extrapolated to other sites at larger scales [127].

In addition to the aforementioned local approach, there is much to be gained by wedding regional-to continental-scale mycorrhizal fungal community characterizations, environmental measurements and the best new modeling approaches to develop a more general understanding of the relationship between mycorrhizal fungal communities and their environment $[7,31,39,49,54,65,127]$. This approach would make us begin to develop species-or community-environment predictive models sufficiently accurate that for any site we could predict the potential pool of dominant fungal taxa [54]. While ambitious, this method is essential in order to predict species-environment relationships beyond a narrow set of sites [45-50,52].

A major motivation for the above effort is the high rate of human-accelerated environmental change, including elevated atmospheric ozone, $\mathrm{CO}_{2}$, nitrogen deposition, climate change and land use/land cover change [33,41-54,129-132]. It is a clear fact that these changes can affect mycorrhizal fungal species, but it is also clear that we do not yet have data sets sufficiently saturated, or models sufficiently powerful, to determine the exact nature, timing and spatial pattern of fungal community responses. This is also the case for the relationship between higher plant community and environment [120,127-129]. Given that mycorrhizal fungi are phylogenetically and functionally diverse, consume a significant portion of global terrestrial pro- duction, play a critical role in nutrient cycling and food webs, and exhibit high sensitivity to environmental change, the ability to predict such community responses is of importance to conserving fungal diversity and maintaining ecosystem processes [7,52,75,112,127-147].

\section{Recent experimental results, discussion and progress: stress resistance improvements under global climate change}

Previous gene engineering strategy for plant stress resistance was to express one (in most cases) or several stress-tolerant genes by constitutive or stress-induced promoters [19]. For instance, by introducing betA gene derived from $E$. coli into tobacco and potato, betaine content in the transgenic plants increased to $5 \mu \mathrm{mol} / \mathrm{g}$ (dry weight) and tolerance to salt and cold for the transgenic plants was improved greatly. The goal of recently established plant gene engineering strategy based on transcriptional elements is to improve plant comprehensiveresistance characters $[15,16,29,30]$. Compared with the previous traditional method of introducing or improving individual functional genes, the new strategy will play more important role in plant molecular breeding because modifying regulatory activities of a transcriptional element can influence functions of many genes, easily reaching the aim of improving plant comprehensive resistance (to drought, salinity, freezing, diseases, UV-B and others) $[93,95,117]$. Through constitutively overexpressing DERB1A, plant stress-responsive genes, Kin1, cor6.6/Kin2, cor15a, cor47/rd17, ord10 got higher expression and obtained transgenic Arabidopsis plants were resistant to drought, cold and salinity. Other related studies also provided a solid evidence for high efficiency of the above methodology.

Dotson (2005) reported that by transferring a transcriptional element into Arabidopsis, which was thought previously not to be related to plant drought response, he obtained many transgenic plants highly resistant to soil water deficits on the basis of selecting the Arabidopsis community with higher expression (http://www.int1-pag.org/13/abstracts/PAG13-W006.htm1). By further introducing he member of this transcriptional element family into soybean, transgenic soybean lines were cultured and they were resistant to soil water deficits in greenhouse and field. This indicated that the function of this transcriptional element family was characteristic of conservativeness among diverse plant species. So, it is possible to obtain expected same stress-resistant phenotype by genetically modifying transcriptional elements [117]. Besides, some transcriptional elements not only regulate metabolic pathways, but also influence transport and allocation of secondary metabolites. Plant secondary metabolism plays an important role in plant responding to environmental stresses. Long-step progress has taken place in terms of introducing transcriptional elements to regulate targeted pathways $[93,95,108,136,141]$.

It is important to remember the fact that some transcriptional elements may regulate several metabolic pathways and one metabolic pathway may need orchestrated regulation from some transcriptional elements, which is the nature of plant gene regulatory network system $[7,95,96,101,102,125,126]$. So, in 
some cases, only introducing a transcriptional element cannot obtain targeted phenotype and may lead to metabolic unbalance in plants. In addition, because of coordinated evolution of transcriptional elements and their regulating metabolic pathways the genetically modifying strategy for the same transcriptional element could produce different phenotypes in different plant species. These issues need deeper exploration to establish an efficient genetically modifying system by transcriptional elements and their network system for improving plant stress resistance and global eco-environment and feeding the world $[101,102,120]$.

\section{Conclusions and perspectives}

Plants are different from animals in many aspects $[17,56,69,119]$. The most important difference is that plants are more easily influenced by environmental factors. So, plants have more refine mechanisms to regulate themselves from molecular level to ecosystem to respond to environmental changing. For instance, there are many coding-protein genes downstream only for osmotic regulation in environmental stress resistance. Under the above background, plants are quite different animals in their gene regulatory network system [119]. Nerve systembased or nerve system-like-based structure and hormones are composed of the body for gene expression in animal network system, leading to animal activeness $[69,101,102]$. In addition, developmental programming cannot be easily effected by environmental cues [69,101-109,119]. Plants are always passive for dealing with environmental succession. Understanding plant gene regulatory network system under changing environment is a big challenge. Nowadays, there are indeed many favorable conditions for charting this blueprint, including much available data from Arabidopsis, rice, grass, yeast and fruit fly, but the range of tested plants is very much limited, many stress-responsive genes have not been unified in terms of their refine functions, and many genes involved in environmental stresses are interacted and overlapped, which have led to incorrect placing of key genes (gene effectors) and signal molecules in the whole plant gene regulatory network system. Besides, much data sets are from under condition of one type of stresses. It is a fact that plants always confront more than two kinds of individual environmental stresses or their combination simultaneously in field $[68,72,73]$. Although drawing plant gene regulatory network system with great details and complete pathways is impossible currently, the basic draft for this blueprint has been summarized in the recent publications $[69,101,102,106,120,121,126,147]$. This draft was established in combination with the recent advance in this hot topic and from the context of development, which will provide instructions for insights into understanding of higher plant refine adaptation to environmental stresses and sustainable developmental utilization of environmental resources.

\section{Acknowledgements}

Dr. Wu Gang's laboratory is grateful for the support from National Economic Development Committee of China, National Natural Science Foundation of China (No. 40473054), and
Achievement Transformation Foundation of Agricultural Science \& Technology (No. 05EFN216600446) (to Wu Gang), Specialized Initiation Foundation of Excellent Ph.D. Dissertation of Chinese Academy of Sciences and National Science \& Technology Supporting Plan of China (2006BAC15B03) (to Shao Hong-Bo). Many thanks are given to Dr. Ohshima for his critically reading the manuscript. Special thanks are also extended to two reviewers for their better suggestions.

\section{References}

[1] H. Abbad, S.E.L. Jaafari, J. Bort, J.L.C. Araus, Comparison of flag leaf and ear photosynthesis with biomass and grain yield of durum wheat under various water conditions and genotypes, Agron. Sus. Dev. 24 (2004) 19-28.

[2] N. Agraval, P.V.N. Dasaradhi, A. Mohmmed, et al., RNA interference: biology, mechanism, and application, Microbiol. Mol. Biol. Rev. 67 (2003) 657-685.

[3] V. Andjelkovic, R. Thompson, Changes in gene expression in maize kernel in response to water and salt stress, Plant Cell Rep. 25 (2006) 71-79.

[4] Y. An, S.Q. Wang, Z.H. Zhou, et al., Plant nitrogen concentration, use efficiency, and contents in a tall grass prairie ecosystem under experimental warming, Global Change Biol. 11 (2005) 1733-1744.

[5] H.P. Bais, R. Vepachedu, S. Gilroy, R.M. Callaway, J.M. Vivanco, Allelopathy and exotic plant invasion: from molecules and genes to species interaction, Science 301 (2003) 1377-1380.

[6] J.M. Barea, M.J. Pozo, R. Azcon, C. Azcon-Aguilar, Microbial cooperation in the rhizosphere, J. Exp. Bot. 56 (2005) 1761-1778.

[7] P. Bauer, Z. Bereczkey, Gene networks involved in iron acquisition strategies in plants, Agron. Sus. Dev. 23 (2003) 447-454.

[8] J. Braam, In touch: plant responses to mechanical stimuli, New Phytol. 165 (2005) 373-389.

[9] M.A. Beer, S. Tavazoie, Predicting gene expression from sequence, Cell 117 (2004) 185-198.

[10] A.D. Bradshaw, Unravelling phenotypic plasticity — why should we both? New Phytol. 170 (2006) 644-648.

[11] R.W. Brooker, Plant-plant interactions and environmental change, New Phytol. 171 (2006) 271-284.

[12] M. Boudsocq, C. Lauriere, Osmotic signaling in plants. Multiple pathways mediated by emerging kinase families, Plant Physiol. 138 (2005) 1185-1194.

[13] J.S. Boyer, Plant productivity and environment potential for increasing crop plant productivity, genotypic selection, Science 218 (1982) 443-448.

[14] V. Chinnusamy, K. Schumaker, J.K. Zhu, Molecular genetic perspectives on cross-talk and specificity in abiotic stress signaling in plants, J. Exp. Bot. 55 (2004) 225-236.

[15] M.M. Chaves, M.M. Oliveira, Mechanisms underlying plant resilience to water deficits: prospects for water-saving agriculture, J. Exp. Bot. 55 (2004) 2365-2384.

[16] M.M. Chaves, J. Maroco, J. Pereira, Understanding plant responses to drought-from genes to the whole plant, Funct. Plant Biol. 30 (2003) 239-2647.

[17] D. Charlesworth, B. Charlesworth, G.A. McVean, Genome sequences and evolutionary biology, a two-way interaction, Trends Ecol. Evol. 16 (2001) 235-242.

[18] J.E.K. Cooke, M. Weih, Nitrogen storage and seasonal nitrogen cycling in Populus: bridging molecular physiology and ecophysiology, New Phytol. 167 (2005) 19-30.

[19] T. Capell, L. Bassie, P. Christou, Modulation of the polyamine biosynthetic pathway in transgenic rice confers tolerance to drought stress, PNAS 101 (2004) 9909-9914.

[20] P. Casati, V. Walbot, Rapid transcriptome responses of maize(Zea mays)to UV-B irradiated and shielded tissues, Genome Biol. 5 (2004) R16-R28.

[21] Z. Chen, D.R. Gallie, The ascorbic acid redox state controls guard cell signaling and stomatal movement, Plant Cell 16 (2004) 1143-1162. 
[22] A.G. Condon, R.A. Richards, G.J. Rebetke, G.D. Farquhar, Breeding for high water-use efficiency, J. Exp. Bot. 55 (2004) 2447-2460.

[23] X. Deng, J. Phillips, A. Brautigam, et al., A homeodomain leucine zipper gene from Craterostigma plantagineum regulates abiscisic responsive gene expression and physiological responses, Plant Mol. Biol. 61 (2006) 469-489.

[24] X.P. Deng, L. Shan, H.P. Zhang, N.C. Turner, Improving agricultural water use efficiency in arid and semiarid areas of China, Agric. Water Manage. 80 (2006) 23-40.

[25] J. Doebley, L. Lukens, Transcriptional regulators and the evolution of plant form, Plant Cell 10 (1998) 1075-1082.

[26] J.A. De Ronde, R.N. Laurie, T. Caetano, et al., Comparative study between transgenic and non-transgenic soybean lines proved transgenic lines to be more drought tolerant, Euphytica 138 (2004) 123-132.

[27] A.M. Dufty Jr., J. Clobert, A.P. Moller, Hormones, developmental plasticity and adaptation, Trends Ecol. Evol. 17 (2002) 190-196.

[28] E.A. Eckardt, H.T. Cho, R.M. Perrin, et al., Plant biology 2001, Plant Cell 13 (2001) 2165-2173.

[29] D.A. Eisenbarth, A.R. Weig, Dynamics of aquaporins and water relations during hypocotyls elongation in Ricinus communis L. seedlings, J. Exp. Bot. 56 (2005) 1831-1842.

[30] European plant science organization (EPSO). European plant science: a field of opportunities. J Exp Bot 56 (2005) 1699-1709.

[31] B. Eric De la, J.L. Andrade, Challenges to plant mega-diversity: how environmental physiology can help, New Phytol. 167 (2005) $5-8$.

[32] D. Eapen, M.L. Barroso, G. Ponce, et al., Hydrotropism: root growth responses to water, Trends Plant Sci. 10 (2005) 44-50.

[33] J.Y. Fang, A.P. Chen, C.H. Peng, S.Q. Zhao, L.J. Ci, Changes in forest biomass carbon storage in China between 1949 and 1998, Science 292 (2001) 2320-2322.

[34] O. Fiehn, Metabolomics-the link between genotypes and phenotypes, Plant Mol. Biol. 48 (2002) 155-171.

[35] B.C. Forde, J.F. Harper, L. Kochian, Focus on plant nutrition, Plant Physiol. 136 (2004) 2437.

[36] K.A. Franklin, G.C. Whitelam, Light signals, phytochromes and crosstalk with environmental cues, J. Exp. Bot. 55 (2004) 271-276.

[37] C.H. Foyer, G. Noctor, Oxidant and antioxidant signaling in plants: a reevaluation of the concept of oxidative stress in a physiological context Plant Cell Environ. 28 (2005) 1056-1071.

[38] R.W. Gesch, I.H. Kang, M. Gallo-Meagher, et al., Rubisco expression in rice leaves is related to genotypic variation of photosynthesis under elevated growth $\mathrm{CO}_{2}$ and temperature, Plant Cell Environ. 26 (2002) 98-107.

[39] P.J. Gregory, Roots, rhizosphere and soils: the route to a better understanding of soil science? Eur. J. Soil. Sci. 57 (2006) 2-12.

[40] C. Gapper, L. Dolan, Control of plant development by reactive oxygen species, Plant Physiol. 141 (2006) 341-345.

[41] A.K. Grennan, Regulation of starch metabolism in Arabidopsis leaves, Plant Physiol. 142 (2006) 1343-1345.

[42] N.G. Halford, M. Paul, Carbon metabolite sensing and signaling, Plant Biotechnol. J. 1 (2003) 381-398.

[43] M.Y. Hiral, M. Yano, D.B. Goodenowe, et al., Integration of transcriptomics and metabolomics for understanding of global responses to nutritional stresses in Arabidopsis thaliana, PNAS 101 (2004) 1-6.

[44] P. Hinsinger, G.R. Gobran, P.J. Gregory, et al., Rhizosphere geometry and heterogeneity arising from root-mediated physical and chemical processes, New Phytol. 168 (2005) 293-303.

[45] P. Hinsinger, C. Plassard, C. Tang, B. Jaillard, Origins of root-induced $\mathrm{pH}$ changes in the rhizospere and their responses to environmental constraints: a review, Plant Soil 248 (2003) 43-59.

[46] A. Hodge, The plastic plants: root responses to heterogeneous supplies of nutrients, New Phytol. 162 (2004) 9-24.

[47] G.T. How, A.M. Brunner, An evolving approach to understanding plant adaptation, New Phytol. 167 (2005) 1-5.

[48] S.K. Hong, J.A. Lee, Global environmental changes in terrestrial ecosystems. International issues and strategic solutions: introduction, Ecol. Res. 21 (2006) 783-787.
[49] E.A. Hobbie, T.R. Horton, Evidence that saprotrophic fungi mobilize carbon and mycorrhizal fungi mobilize nitrogen during litter decomposition, New Phytol. 173 (2007) 447-449.

[50] M.W. Humphreys, R.S. Yadav, A.J. Cairns, et al., A changing climate for grassland research, New Phytol. 169 (2006) 9-26.

[51] Y.C. Hu, H.B. Shao, L.Y. Chu, G. Wu, Relationship between water use efficiency (WUE)and production of different wheat genotypes at soil water deficit, Colloids Surf. B: Biointerf. 53 (2006) 271-277.

[52] R. Hyvonen, G.I. Agren, S. Linder, et al., The likely impact of elevated $\left[\mathrm{CO}_{2}\right]$, nitrogen deposition, increased temperature and management on carbon sequestration in temperate and boral forest ecosystems: a literature review, New Phytol. 173 (2007) 463-480.

[53] A.D.B. Leakey, M. Uribelarrea, E.A. Ainsworth, et al., Photosynthesis, productivity, and yield of maize are not affected by open-air elevation of $\mathrm{CO}_{2}$ concentration in the absence of drought, Plant Physiol. 140 (2006) $779-790$.

[54] M.S. Lee, W.H. Mo, H. Koizumi, Soil respiration of forest ecosystems in Japan and global implications, Ecol. Res. 21 (2006) 828-839.

[55] J.Y. Lee, M. Levesque, P.N. Benfey, High-throuput RNA isolation technologies. New tools for high-resolution gene expression profiling in plant systems, Plant Physiol. 138 (2005) 585-590.

[56] R.L. Lenski, J.E. Barrick, C. Ofria, Balancing robustness and evolvability, PLoS Biol. 4 (2006) e428.

[57] J.X. Li, X.Q. Wang, M.B. Watson, S.M. Assmann, Regulation of abscisic acid-induced stomatal closure and anion channels by guard cell AAPK kinase, Science 287 (2000) 300-302.

[58] J.G. Liu, J. Diamond, China's environment in a globalizing world, Nature 435 (2005) 1179-1186.

[59] H.S. Liu, F.M. Li, Photosynthesis, root respiration, and grain yield of spring wheat in response to surface soil drying, Plant Growth Regul. 45 (2005) 149-154.

[60] B.D. Lindahl, K. Ihrmark, J. Boberg, et al., Spatial separation of litter decomposition and mycorrhizal nitrogen uptake in a boreal forest, New Phytol. 173 (2007) 611-620.

[61] S.D. Lokhandle, K. Ogawa, A. Tanaka, et al., Effect of temperature on ascorbate peroxidase activity and flowering of Arabidopsis thaliana ecotypes under different light conditions, J. Plant Physiol. 160 (2003) $57-64$.

[62] Q. Liu, Y. Zhang, S.Y. Chen, Plant protein kinase genes induced by drought,high salt and cold stresses, Chin. Sci. Bull. 45 (2000) 1153-1157.

[63] X.N. Liu, Wm Vance Baird, Identification of a novel gene, HAABRC5, from Helianthus annuus (Asteraceae) that is upregulated in response to drought, salinity, and abscisic acid, Am. J. Bot. 91 (2004) 184-191.

[64] M.Y. Jiang, J.H. Zhang, Abscisic acid and antioxidant defense in plant cells, Acta Bot. Sinica 46 (2004) 1-9.

[65] D. Johnson, M. Ijdo, D.R. Genney, et al., How do plants regulate the function, community structure, and diversity of mycorrizal fungi? J. Exp. Bot. 56 (2005) 1751-1760.

[66] S.Z. Kang, J.H. Zhang, Controlled alterate partial root-zone irrigation:its physiological consequences and impact on water use efficiency, J. Exp. Bot. 55 (2004) 2437-2446.

[67] A. Kolbe, S.N. Oliver, A.R. Fernie, et al., Combined transcript and metabolite profiling of Arabidopsis leaves reveals fundamental effects of the thiol-disulfide status on plant metabolism, Plant Physiol. 141 (2006) 412-422.

[68] J.A. Kreps, Y.J. Wu, H.S. Chang, et al., Transcriptome changes for Arabidopsis in response to salt, osmotic, and cold stress, Plant Physiol. 130 (2002) 2129-2141.

[69] E.M. Meyerowitz, Plants compared to animals: the broadest comparative study of development, Science 295 (2002) 1482-1485.

[70] E. McCormack, Y.C. Tsai, J. Braam, Handling calcium signaling: Arabidopsis CaMs and CMLs, Trends Plant Sci. 10 (2005) 383-389.

[71] M. Miyao, Molecular evolution and genetic engineering of $\mathrm{C}_{4}$ photosynthetic enzymes, J. Exp. Bot. 54 (2003) 179-189.

[72] R. Mittler, Abiotic stress, the field environment and stress combination, Trends Plant Sci. 11 (2006) 15-19.

[73] R. Mittler, Oxidative stress, antioxidants and stress tolerance, Trend Plant Sci. 7 (2002) 855-862. 
[74] S. Munne-Bosch, L. Alegre, Die and let live: leaf senescence contributes to plant survival under drought stress, Funct. Plant Biol. 31 (2004) 203-216.

[75] J.A.W. Morgan, G.D. Bending, P.J. White, Biological costs and benefits to plant-microbe interactions in the rhizosphere, J. Exp. Bot. 56 (2005) $1729-1739$.

[76] J.F. Ma, Role of silicon in enhancing the resistance of plants to biotic and abiotic stresses, Soil Sci. Plant Nutr. 50 (2004) 11-18.

[77] R. Munns, Comparative physiology of salt and water stress, Plant Cell Environ. 25 (2003) 239-256.

[78] R. Munns, Genes and salt tolerance: bringing them together, New Phytol. 167 (2005) 645-663.

[79] P.M. Mullineaux, S. Karpinski, N.R. Baker, Spatial dependence for hydrogen peroxide-directed signaling in light-stressed plants, Plant Physiol. 141 (2006) 346-350.

[80] H. Nakagami, A. Pitzschke, H. Hirt, Emerging MAP kinase pathways in plant stress signalling, Trends Plant Sci. 10 (2005) 339-346.

[81] M. Noble, M. Mayer-Proschel, C. Proschel, Redox regulation of precursor cell function: Insights and paradoxes, Antioxid. Redox Signal. 7 (2005) 1456-1467.

[82] P. Neumann, Salinity resistance and plant growth revisited, Plant Cell Environ. 20 (1997) 1193-1198.

[83] C. Nguyen, Rhizodeposition of organic $\mathrm{C}$ by plants: mechanisms and controls, Agron. Sus. Dev. 23 (2003) 375-396.

[84] C.M. Ozanne, D. Anhuf, S.L. Boulter, et al., Biodiversity meets the atmosphere: a global view of forest canopies, Science 301 (2003) 183-186.

[85] G.M. Pastori, C.H. Foyer, Common components, networks, and pathways of cross-tolerance to stress. The central role of "Redox" and abiscisic acid-mediated controls, Plant Physiol. 129 (2002) 460-468.

[86] L.W. Parfrey, E. Barbero, E. Lasser, M. Dunthorn, D. Bhattacharya, Evaluating support for the current classification of eukaryotic diversity, PLoS Genet. 2 (2006) e220.

[87] R.M. Pitman, Wood ash use in forestry - a review of the environmental impacts, Forestry 79 (2006) 563-588.

[88] A. Pitzschke, H. Hirt, Mitogen-activated protein kinases and reactive oxygen species signaling in plants, Plant Physiol. 141 (2006) 351-356.

[89] D.J. Read, J. Perez-Moreno, Mycorrhizas and nutrient cycling in ecosystems-a journey towards relevance? New Phytol. 157 (2003) 475-492.

[90] M.C. Rillig, D.L. Mummey, Mycorrhizas and soil structure, New Phytol. 171 (2006) 41-53.

[91] A.A. Rosenberg, M.J. Fogarty, M.P. Sissenwine, et al., Achieving sustainable use of renewable resources, Science 262 (1993) 828-829.

[92] O. Schumpp, H. Gherbi, J. Escoute, et al., In situ hybridization of a radioactive RNA on resin-embedded legume root-nodule sections: a tool for observing gene expression in the rhizosphere? Agron. Sus. Dev. 23 (2003) 489-493.

[93] Y. Sakuma, K. Maruyama, Y. Osakabe, et al., Functional analysis of an Arabidopsis transcription factor, DREB2A, involved in droughtresponsive gene expression, Plant Cell 18 (2006) 1292-1309.

[94] C.D. Schlighting, Phenotypic plasticity in plants, Plant Species Biol. 17 (2002) 85-88.

[95] K. Shinozaki, E.S. Dennis, Cell signaling and gene regulation global analyses of signal transduction and gene expression profiles, Curr. Opin. Plant Biol. 6 (2003) 405-409.

[96] C. Somerville, J. Dangl, Plant biology in 2010, Science 290 (2000) 2077-2078.

[97] H.B. Shao, Z.S. Liang, M.A. Shao, Roles of ABA signal transduction during higher plant seed maturation and germination, Forest. Stud. China 5 (2003) 42-51.

[98] H.B. Shao, Z.S. Liang, M.A. Shao, B.C. Wang, Changes of some physiological and biochemical indices for soil water deficits among 10 wheat genotypes at seedling stage, Colloids Surf. B: Biointerf. 41 (2005) 107-113.

[99] H.B. Shao, L.Y. Chu, G. Wu, J.H. Zhang, Z.H. Lu, Y.C. Hu, Changes of some anti-oxidative physiological indices under soil water deficits among 10 wheat (Triticum aestivum L.) genotypes at tillering stage, Colloids Surf. B: Biointerf. 54 (2007) 143-149.
[100] H.B. Shao, X.Y. Chen, L.Y. Chu, X.N. Zhao, G. Wu, Y.B. Yuan, C.X. Zhao, Z.M. Hu, Investigation on the relationship of proline with wheat anti-drought under soil water deficits, Colloids Surf. B: Biointerf. 53 (2006) 113-119.

[101] H.B. Shao, Q.J. Guo, L.Y. Chu, X.N. Zhao, Z.L. Su, Y.C. Hu, J.F. Cheng, Understanding molecular mechanism of higher plant plasticity under abiotic stress, Colloids Surf. B: Biointerf. 54 (2007) 37-45.

[102] H.B. Shao, S.Y. Jiang, F.M. Li, L.Y. Chu, C.X. Zhao, M.A. Shao, X.N. Zhao, F. Li, Some advances in plant stress physiology and their implications in the systems biology era, Colloids Surf. B: Biointerf. 54 (2007) $33-36$.

[103] H.B. Shao, L.Y. Chu, G. Wu, J.H. Zhang, Z.H. Lu, Where is the road to bio-watersaving for the globe? Colloids Surf. B: Biointerf. 55 (2007) 153-159.

[104] H.B. Shao, L.Y. Chu, C.X. Zhao, Q.J. Guo, X.A. Liu, J.M. Ribaut, Plant gene regulatory net work system under abiotic stress, Acta Biol. Sezeged. 50 (2006) 1-9.

[105] H.B. Shao, Z.S. Liang, M.A. Shao, Q. Sun, Z.M. Hu, Investigation on dynamic changes of photosynthetic characteristics of 10 wheat (Triticum aestivum $L$.) genotypes during two vegetative-growth stages at water deficits, Colloids Surf. B: Biointerf. 43 (2005) 221-227.

[106] H.B. Shao, Z.S. Liang, M.A. Shao, Adaptation of higher plants to stresses and stress signal transduction, Acta Ecol. Sinica 25 (2005) 1871-1882.

[107] H.B. Shao, Z.S. Liang, M.A. Shao, Dynamic changes of anti-oxidative enzymes of 10 wheat genotypes at soil water deficits, Colloids Surf. B: Biointerf. 42 (2005) 187-195.

[108] H.B. Shao, L.Y. Chu, Plant molecular biology in China: opportunities and challenges, Plant Mol. Biol. Rep. 23 (2005) 345-358.

[109] B.J. Shelp, A.W. Brown, D. Faure, Extracellular aminobutyrate mediates communication between plants and other organisms, Plant Physiol. 142 (2006) 1350-1352.

[110] V. Shulaev, D.J. Oliver, Metabolic and proteomic markers for oxidative stress. New tools for reactive oxygen species research, Plant Physiol. 141 (2006) 367-372.

[111] K.K. Shimizu, Purugganan MDEvolutionary and ecological genomics of Arabidopsis, Plant Physiol. 138 (2005) 578-584.

[112] R.T. Voegele, K.W. Mendgen, Meetings: impact of genomics on fungal biology, New Phytol. 173 (2007) 458-462.

[113] Y. Tan, Z.S. Liang, H.B. Shao, F. Du, Effect of water deficits on the activity of anti-oxidative enzymes and osmoregulation among 3 different genotypes of Radix Astragali at seeding stage, Biointerfaces 49 (2006) $60-65$.

[114] M. Tester, A. Basic, Abiotic stress tolerance in grasses. From model plants to crop plants, Plant Physiol. 137 (2005) 791-793.

[115] E. Vranova, D. Inze, F.V. Breusegem, Signal transduction during oxidative stress, J. Exp. Bot. 53 (3720) (2002) 1227-1236.

[116] T.S. Walker, H.P. Bais, E. Grotewold, J.M. Vivanco, Root exudation and rhizosphere biology, Plant Physiol. 132 (2003) 44-51.

[117] W.X. Wang, B. Vinocur, A. Altman, Plant responses to drought, salinity and extreme temperatures: towards genetic engineering for stress tolerance, Planta 218 (2003) 1-14.

[118] X.Q. Wang, H. Ullah, A.M. Jones, et al., G protein regulation of ion channels and abscisic acid signaling in Arabidopsis guard cells, Science 292 (2001) 2070-2072.

[119] J.S. Weitz, P.N. Benfey, N.S. Wingreen, Evolution, interactions, and biological networks, PLoS Biol. 5 (2007) e11.

[120] G. Wu, L.Y. Chu, H.B. Shao, J.W. Cai, Insights into molecular mechanisms of mutual effect between plants and the environment. A review, Agron. Sustain. Dev. 27 (2007) 1-10.

[121] L.M. Xiong, R.G. Wang, G.H. Mao, J.M. Koczan, Identification of drought tolerance determinants by genetic analysis of root response to drought stress and abiscisic acid, Plant Physiol. 142 (2006) 1065-1074.

[122] J.C. Yang, J.H. Zhang, Grain filling of cereals under soil drying, New Phytol. 169 (2006) 223-236.

[123] S.R. Zhang, Q.L. Dang, Effects of soil temperature and elevated atmospheric $\mathrm{CO}_{2}$ concentration on gas exchange, in vivo carboxylation and chlorophyll fluorescence in jack pine and white birch seedlings, Tree Physiol. 25 (2006) 609-617. 
[124] C.X. Zhao, X.P. Deng, S.Q. Zhang, et al., Advances in the studies on water uptake by plant roots, Acta Bot. Sinica 46 (2004) 505-514.

[125] J.K. Zhu, Salt and drought stress signal transduction in plants, Annu. Rev. Plant Biol. 53 (2002) 247-273.

[126] J.K. Zhu, Regulation of ion homeostasis under salt stress, Curr. Opin. Plant Biol. 6 (2003) 441-445.

[127] E.A. Lilleskov, J.L. Parrent, Can we develop general predictive models of mycorrhizal fungal community-environment relationship? New Phytol. 174 (2007) 250-256.

[128] M.G.A. Van der Heijden, T.R. Scheublin, Functional traits in mycorrhizal ecology: their use for predicting the impact of arbuscular mycorrhizal fungal communities on plant growth and ecosystem functioning, New Phytol. 174 (2007) 244-250.

[129] R. Norby, H. Slater, New phytologist and the environment, New Phytol. 174 (2007) 1-3.

[130] L. Lanfranco, The fine-tuning of heavy metals in mycorrhizal fungi, New Phytol. 174 (2007) 3-6.

[131] F. Martin, H. Slater, New phytologist—an evolving host for mycorrhizal research, New Phytol. 174 (2007) 225-228.

[132] J.I. Sprent, Evolving ideas of legume evolution and diversity: a taxonomic perspective on the occurrence of nodulation, New Phytol. 174 (2007) $11-25$.

[133] V. Wiemken, Trehalose synthesis in ectomycorrhizas - a driving force of carbon gain for fungi? New Phytol. 174 (2007) 228-230.

[134] Y. Shachar-Hill, Quantifying flows through metabolic networks and the prospects for fluxomic studies of mycorrhizas, New Phytol. 174 (2007) 235-240.

[135] M.-B. Bogeat-Triboulot, M. Brosche, J. Renaut, et al., Gradual soil water depletion results in reversible changes of gene expression, protein profiles, ecophysiology, and growth performance in Populus euphratica, a popular growing in arid regions, Plant Physiol. 143 (2007) 876892.

[136] W.H. Cao, J. Liu, X.J. He, et al., Modulation of ethylene responses affects plant salt-stress responses, Plant Physiol. 143 (2007) 707719.
[137] Y. Goldgur, S. Rom, R. Ghirlando, et al., Desiccation and zinc binding induce transition of tomato abiscisic acid stress ripening 1 , a water stressand salt stress-regulated plant-specific protein,from unfolded to folded state, Plant Physiol. 143 (2007) 617-628.

[138] C. Dardick, J. Chen, T. Richter, et al., The rice kinase database. A phylogenomic database for the rice kinome, Plant Physiol. 143 (2007) 579-586.

[139] G.E. Schaller, K. Doi, Ildoo Hwang, et al., Nomenclature for twocomponent signaling elements of rice, Plant Physiol. 143 (2007) 555-557.

[140] E.E. Kassis, N. Cathala, H. Rouached, et al., Characterization of a selenate-resistant Arabidopsis mutant. Root growth as a potential target for selenate toxicity, Plant Physiol. 143 (2007) 1231-1241.

[141] B. Rymen, F. Fiorani, F. Kartal, et al., Cold nights impair leaf growth and cell cycle progression in maize through transcriptional changes of cell cycle genes, Plant Physiol. 143 (2007) 1429-1438.

[142] S. Munemasa, K. Oda, M. Watanabe-Sugimoto, et al., The coronativeinsensitive 1 mutation reveals the hormonal signaling interaction between abiscisic acid and methyl jasmonate in Arabidopsis guard cells. Specific impairment of ion channel activation and second messenger production, Plant Physiol. 143 (2007) 1398-1407.

[143] W. Zhang, L.M. Fan, W.H. Wu, Osmo-sensitive and stretch-activated calcium-permeable channels in Vicia faba guard cells are regulated by actin dynamics, Plant Physiol. 143 (2007) 1140-1151.

[144] F.C. Chen, S.S. Wang, S.M. Chaw, et al., Plant gene and alternatively spliced variant annotator. A plant genome annotation pipeline for rice gene and alternatively spliced variant identification with cross-species expressed sequence tag conservation from seven plant species, Plant Physiol. 143 (2007) 1086-1095.

[145] J. Ramos, M.R. Clemente, L. Naya, et al., Phytochelatin synthases of the model legume Lotus japonicus. A small multigene family with differential response to cadmium and alternatively spliced variants, Plant Physiol. 143 (2007) 1110-1118.

[146] R. Jorgensen, 21st century plant biology: Viva la Revolucio'n? Plant Cell 19 (2007) 389-390.

[147] N.A. Eckardt, Two protein kinases required for ABA signaling in Arabidopsis, Plant Cell 19 (2007) 394. 